\title{
Characterization and evaluation of amorphous carbon thin film (ACTF) for sodium ion adsorption
}

\author{
Mahmoud Fathy $^{1} \cdot$ Mahmoud Ahmed Mousa $^{2} \cdot$ Th. Abdel Moghny ${ }^{1} \cdot$ \\ Ahmed E. Awadallah ${ }^{1}$
}

Received: 29 May 2016/Accepted: 11 July 2017/Published online: 27 July 2017

(c) The Author(s) 2017. This article is an open access publication

\begin{abstract}
The removal of sodium ions from aqueous solutions by adsorption onto amorphous carbon thin film (ACTF) has been studied in batch mode. In this work, the ACTF as new adsorbent was synthesized based on rice straw, then its structure and properties were taken into consideration to study its ability to adsorb sodium ions from synthetic water. The influence of $\mathrm{pH}$, contact time, and temperature of the ion adsorption on ACTF was also studied using batch tests. We found that the contact time of sodium adsorption and its isothermal adsorption studied were described by pseudo-second-order kinetic model and Langmuir isotherm, respectively. Our results indicated that the adsorption of sodium ions on ACTF become be stronger and depends on $\mathrm{pH}$, furthermore, the maximum adsorption capacities of sodium on ACTF recorded 107, 120 and $135 \mathrm{mg} \mathrm{g}^{-1}$ at 35,45 , and $65^{\circ} \mathrm{C}$. The thermodynamic parameters explain that the adsorption of sodium ions on ACTF is a spontaneous process and endothermic reaction. According to adsorption studies, we found that the ACTF can be used effectively for ion chromatography or desalinate sodium ion using ion exchange process in the hybrid desalination process with insignificant loss of adsorption capacity. However, the ACTF has better properties than any other carbon materials obtained from an agricultural byproduct.
\end{abstract}

Keywords Capacity · Carbon - Adsorption - Amorphous · Cellulose $\cdot$ Hybrid desalination

Mahmoud Fathy

fathy8753@yahoo.com; dr.abo_fathy@yahoo.com

1 Egyptian Petroleum Research Institute (EPRI), Cairo, Egypt

2 Faculty of the Science, Banha University, Banha, Egypt

\section{Introduction}

The annually renewable agricultural residues represent an abundant, inexpensive, and available source of renewable lingo-cellulosic biomass, and their utilizations are attracting increased interest around the world, particularly for the production of novel materials for environmentally and friendly industrial utilizations after chemical modification. Surface adjustments of initiating carbon were connected to upgrade the scattering property and adsorption limits of carbon materials, particularly amorphous carbon (Valentini et al. 2004; Reddy and Yang 2008). Amino, carboxyl, and hydroxyl functionalities assume a noteworthy part in developing complex structures in a blend with other utilitarian gatherings or the first structure of the carbon materials (Fathy et al 2016b; Fathy et al. 2015b).

As it is known that the sea water is considered a good source of water, its salinity does not allow it for human consumption. As known from the saline water analysis, the $\mathrm{NaCl}$ represented a major component, where chlorine mass represented about 16 times higher than $\mathrm{Mg}, \sim 22$ times than sulfur, $\sim 48$ times than $\mathrm{Br}$ and $\mathrm{K}$. Similarly, sodium mass represented about 9 times higher than $\mathrm{Mg}, 12$ times to sulfur, 17 times to $\mathrm{K}$ and 180 times higher than $\mathrm{Br}$ and $\mathrm{C}$ (Wang et al. 2010; Zhou et al. 2014). Although the percentage of sodium chloride in seawater is much higher than other salts, their removing only from seawater does not mean that the water becomes safe to drink (Zhu et al. 2014; Nguyen and Nguyen 2015).

There are different methods like reverse osmosis (RO) that can be used to remove sodium ions from saline water, and therefore all the mineral elements, as well as the impurities contained in seawater, are removed, making this close to pure freshwater (Hau et al. 2014); in addition, the costs of RO per unit volume are lower in the long term. 
The simple process for removal of $\mathrm{NaCl}$ from seawater was obtained through the adsorption or separation of sodium chloride (Yang et al. 2015). Unlike desalination, the energy requirement in adsorption process is very small, and it can even work under gravity. The advantage of nanoscience technology is reflected in the preparation of ACTF that possess a pores and surface structures leading to the exploration of nonmaterial for adsorption process (Bevilacqua et al. 2015). Recently, instead of pores embedded in polymer membrane, the native pores of carbon nanostructures, particularly ACTF, will have caught attention for absorption of sodium from wastewater (Deng et al. 2015).

Hybrid configurations encompass straightforward structures with a low degree of coupling between membrane and ion exchange processes for adsorption or ion exchange process, as well as with several desalination processes connected in series or parallel (Clarke et al. 2015; Cohen-Tanugi and Grossman 2015; Date et al. 2015).

There is the challenge between those responsible scientists of desalination plants and Environmental scientists, where the desalination plants produce chemical and thermal impact pollutants affect the surrounding environment, also a third challenge in the construction of desalination plants with ideal designs (da Silva et al. 2015; Da et al. 2015; Del-Pilar-Ruso et al. 2015; Deshmukh et al. 2015; Dinda et al. 2015).

The goal of this work is to assess the adsorption of sodium ions on ACTF produced from rice straw waste. To accomplish this objective, the impact of trial climate, such as contact time, $\mathrm{pH}$ scale, and temperature, on the adsorption process of sodium ions was analyzed. The adsorption thermodynamics and energy forms on ACTF were also considered.

\section{Materials and methods}

\section{Characterization of adsorbent}

The SEM morphological image was done using Carl Zeiss (Germany). The TEM analysis was done using a jouel2000 electron microscope at $200 \mathrm{kV}$. Data of X-ray diffraction (XRD) were obtained by (Bruker AXS, Germany) (Cu $k_{\alpha 1}$ radiation, $\lambda=1.54059 \AA)$. The synthesized ACTF was characterized using fourier transform infrared (FTIR) spectroscopy (Nicolet 8700, Thermo Scientific, USA) with an Attenuated Total Reflection (ATR) unit (Zn Se crystal, $\left.45^{\circ} \mathrm{C}\right)$.

In addition, Raman microscope model (SENTERRA, Bruker, Germany) was also used to characterize ACTF, at laser wavelength of $532 \mathrm{~nm}$ and power $10 \mathrm{~mW}$

\section{Preparation of the cobalt silicate nano particles}

$4.0 \mathrm{~g}$ freshly prepared cobalt silicate was vigorously stirred in $200 \mathrm{ml}$ ethanol for $30 \mathrm{~min}$ at $45^{\circ} \mathrm{C}$, and then $40 \mathrm{ml}$ water and $4 \mathrm{ml}(1.4 \mathrm{M}) \mathrm{NaOH}$ were added to the above suspension. The powder was separated and dried at $50^{\circ} \mathrm{C}$ for 8 $\mathrm{h}$ in a vacuum oven to obtain cobalt silicate nanoparticles as described in references (Bertrand-Drira et al. 2015).

\section{Rice straw pretreatments}

Rice straw pretreatment process was carried out through solubilization of cellulose in dilute acid for $60 \mathrm{~min}$ at $120{ }^{\circ} \mathrm{C}$ using $1 \%(\mathrm{wt} / \mathrm{wt}$ ) sulphuric acid; the delignification process was completed at $120^{\circ} \mathrm{C}$ for $60 \mathrm{~min}$ using $1 \mathrm{M}$ sodium hydroxide. During the delignification process, both lignin and silica present in the pretreated rice straw removed into the black liquor.

\section{Chemical exfoliation of cellulose}

$5 \mathrm{~g}$ of cellulose were added to $5 \mathrm{ml}$ concentrated sulfuric acid in the presence of $0.1 \mathrm{~g}$ silica and then steered for $10 \mathrm{~min}$. The filtrate was washed with hot water until $\mathrm{pH} 7$ and kept in the oven at $40{ }^{\circ} \mathrm{C}$ for $6 \mathrm{~h}$. The prepared cellulose was poured in a flask in the presence of $0.01 \mathrm{~g}$ cobalt silicate nanoparticles and heated up to $40{ }^{\circ} \mathrm{C}$ for $30 \mathrm{~min}$. The prepared carbon nonmaterials was left to cool for $1 \mathrm{~h}$ and dried in a vacuum oven for $24 \mathrm{~h}$ at $50-70{ }^{\circ} \mathrm{C}$.

\section{Adsorption experiments}

To study the adsorption experiments, $10 \mathrm{ml}$ sodium ion solution was added to $1 \mathrm{mg}$ ACTF in bottles and placed in a water bath for $2 \mathrm{~h}$ at certain $\mathrm{pH}$; an ultrasonic bath was used to maintain the certain temperature (Zhu et al. 2015). An ultrasonic bath was used to maintain the temperature. A $0.4 \mu \mathrm{m}$ microfiltration membrane filter was used to filtered the aqueous samples. Finally, the concentrations of sodium ions infiltrate were determined using atomic absorption spectroscopy (AAS) (Zhao et al. 2013).

\section{Adsorption kinetic measurements}

Adsorption kinetic study was carried out by dissolving analytical grade sodium chloride in distilled water to prepare sodium stock solution containing $500 \mathrm{mg} / \mathrm{L}$, then adding different sodium concentrations to fixed adsorbent dose at constant temperature in shaking water bath at $\left(25{ }^{\circ} \mathrm{C} \pm 02\right)$. The $\mathrm{pH}$ of the solution was maintained at a defined value by manually adding $0.1 \mathrm{M} \mathrm{H}_{2} \mathrm{SO}_{4}$ and/or $\mathrm{NaOH}$ solutions. The flask was capped and stirred magnetically at $700 \mathrm{rpm}$ for $240 \mathrm{~min}$ to ensure approximate 


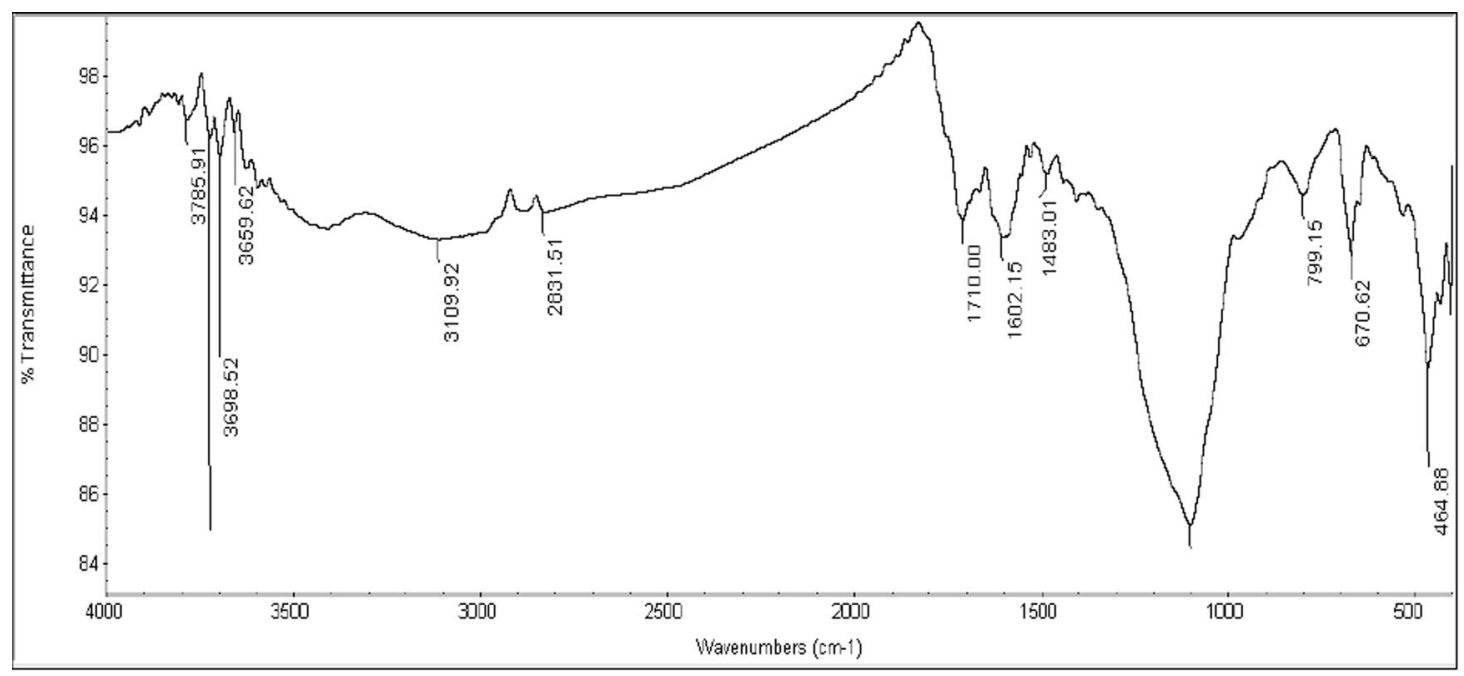

Fig. 1 FTIR of amorphous carbon thin film from rice straw

equilibrium. At the end of the adsorption period, the solution was filtered through a $0.45 \mu \mathrm{m}$ membrane filter and then analyzed for sodium ions species.

\section{Effect of pH}

To measure the effect of $\mathrm{pH}$ on $\mathrm{Na}^{+}$absorption, the $\mathrm{pH}$ solution values ranged between 2.1 and 12.0 were prepared using buffered solution of $\mathrm{HCl}$ and $\mathrm{NaOH}$ at $35{ }^{\circ} \mathrm{C}$. All $\mathrm{Na}^{+}$experiment were conducted at ideal approval pH 7(Yari et al. 2015).

\section{Kinetic and isothermal study}

The effect of contact time on $\mathrm{Na}^{+}$ions adsorption on ACTF was studied in time ranging between 5 and $120 \mathrm{~min}$. Different initial sodium ions concentrations ranged between 50 and $500 \mathrm{mg} \mathrm{L}^{-1}$ were used to perform the adsorption isotherm experiments. The thermodynamic adsorption experiments were studied at 35,45 , and $65^{\circ} \mathrm{C}$. The difference between the initial concentration and the equilibrium concentration was used to determine the amount of adsorbed $\mathrm{Na}^{+}$(Xia et al. 2014, Yang et al. 2014).

\section{Results and discussion}

\section{Amorphous carbon thin-film characterization}

\section{FTIR analysis}

FTIR of amorphous carbon thin film prepared from rice straw in Fig. 1 exhibited stretching bands at 3659 and $1100 \mathrm{~cm}^{-1}$ is indicating the presence of $\mathrm{OH}$ and $\mathrm{C}=\mathrm{O}$ functional groups (Zuyi et al. 1995). The $\mathrm{C}=\mathrm{C}$ characteristic peaks of graphene materials are present in the range between $1340-1700 \mathrm{~cm}^{-1}$, the two peaks presented at 1118 $\mathrm{cm}^{-1}$ for $\mathrm{C}-\mathrm{OH}$ stretching and $\mathrm{OH}$ bending vibrations, while the original $\mathrm{C}-\mathrm{H}$ stretching vibrations bands appeared at 2921 and $2852 \mathrm{~cm}^{-1}$. The peaks at 1580 and $1636 \mathrm{~cm}^{-1}$ were due to the stretching vibration of carboxylic group. The spectrum shows that there are a large number of residues including hydroxyl and carboxyl groups. Thereby, they play important roles in the formation of spherical structures (Mehta et al. 2016). The lower intensity peak at $3430 \mathrm{~cm}^{-1}$ was also observed in the control spectrum that was caused by moisture in the sample. Two major peaks at 2919.2 and $2354.8 \mathrm{~cm}^{-1}$ were also seen in the spectrum that corresponding to $\mathrm{C}-\mathrm{H}$ stretching.

\section{Raman analysis}

The Raman spectrum of ACTF given in Fig. 2 displays broadened prominent $\mathrm{G}$ peak at $1592 \mathrm{~cm}^{-1}$; such peak according to the first-order scattering of the $E_{2}$ g mode was shifted from $1582 \mathrm{~cm}^{-1}$ (Reddy and Yang 2008; Singh et al. 2015). The $D$ band at $1363 \mathrm{~cm}^{-1}$ becomes sheltered and showing the reduction in the size of the in-plane $\mathrm{sp}^{2}$ domains because of the extensive oxidation process. This feature of change suggests a decrease in the average size of the $\mathrm{sp}^{3}$ upon oxidation of the exfoliated graphite nanoparticles and the value of $\mathrm{I} / \mathrm{Io}=0.333$ indicates the highly succeed in the preparation of ACTF with a high degree of crystallinity and low defecates.

\section{SEM analysis}

The SEM morphological image of external amorphous carbon thin-film surface in Fig. 3 showed that the surface of carbon activated chemically by cobalt silicates and acid reagent has the best porous structure, because this surface 
Fig. 2 Raman analysis of amorphous carbon thin film from rice straw

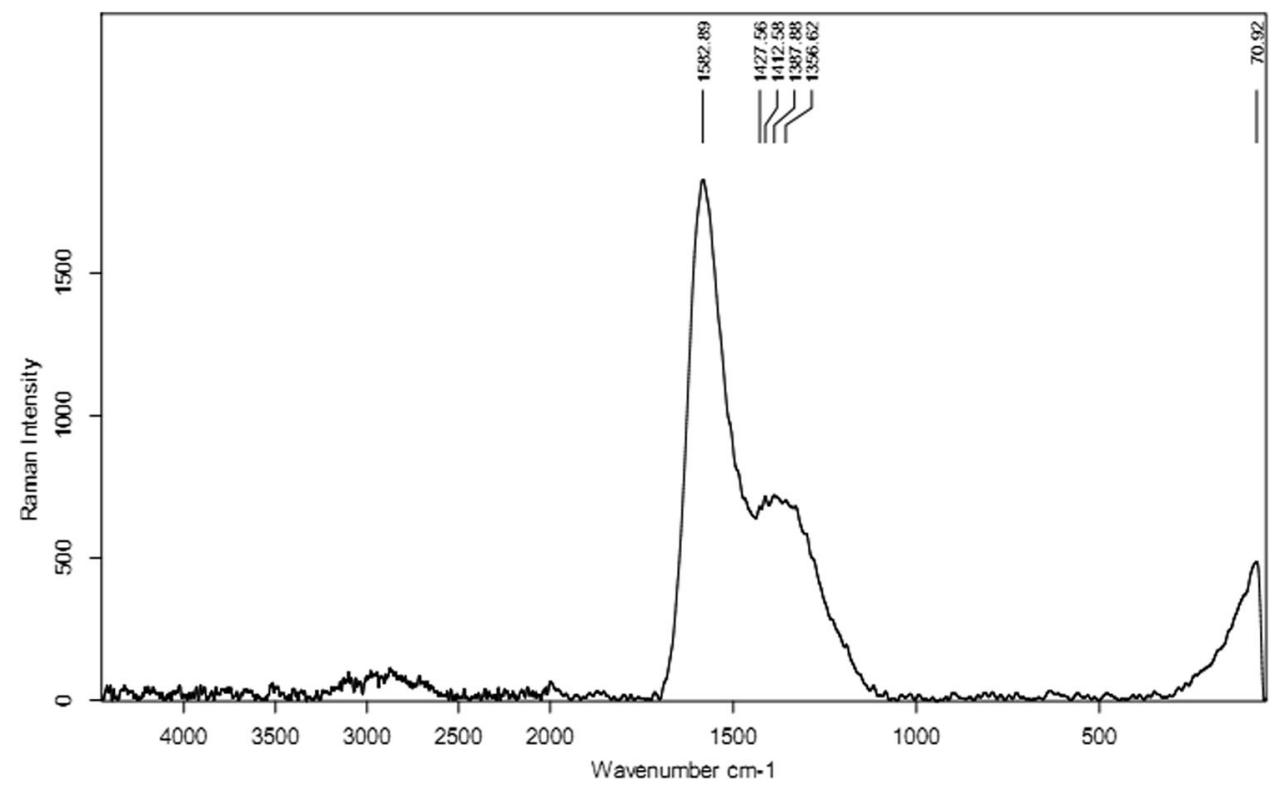

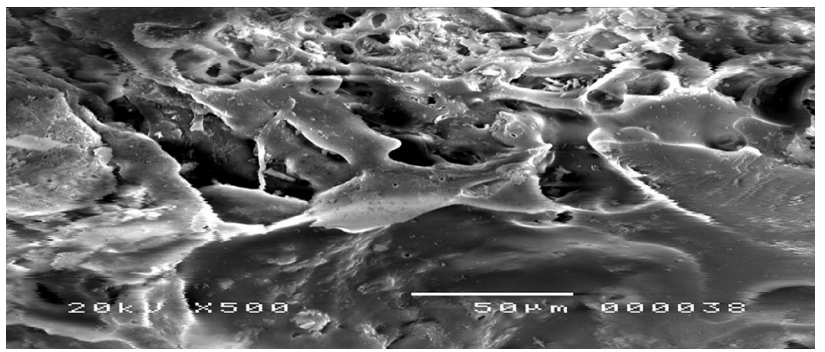

Fig. 3 SEM of amorphous carbon thin film from rice straw

was rich in pores, and consists of more uniform carbon nanoparticles (Fathy et al. 2016a, b, c, d). Comparing with other literature, it is found that the surface of the carbon activated physically had no porous structure except for some occasional cracks (Jodeh et al. 2016). We found that the acidic groups on the surface of ACTF could give numerous adsorption sites and thereby increase its adsorption capacities toward $\mathrm{Na}^{+}$ions. In addition, the morphology image illustrates adhering of ACTF to each other; therefore, the interspaces between ACTF are significantly reduced. Based on our recent SEM analysis, there is the presence of inter-particle repulsions forces between carboxylic groups on the surface of ACTF in smaller sized "globs" of ACTF that result in smaller ACTF aggregates of carboxyl-functionalized ACTF. This feature of result shows that it is possible to use, the functioned ACTF as adsorbents in the treatment of polluted water and sewer water (El-Sayed et al. 2016).

\section{TEM analysis}

TEM morphology of ACTF and the structure of carbon materials surface appear in Fig. 4. The carbon material in

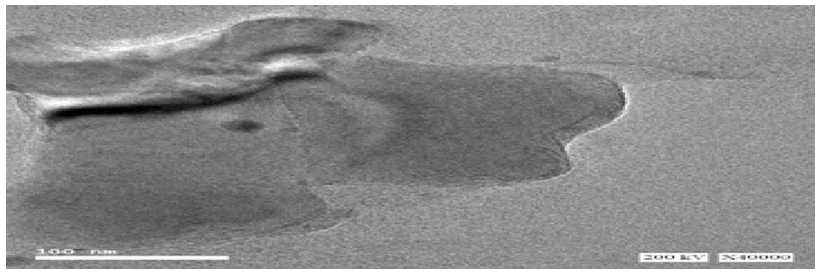

Fig. 4 High-resolution TEM of transparent amorphous carbon thin films

our work shows many various forms and property. After oxidation, TEM pictures of ACTF delegate that the surface of ACTF is not smooth and clean, and there is undeniable change, at first, glance structure. Moreover, the subsequent carbonization and CAS method activation processes produce different nanocarbon with well-controlled morphologies. The commonplace width of ACTF was assessed to be in the scope of $40-100 \mathrm{~nm}$. It will be shown that this activated nanocarbon (ACTF) with increased surface areas contributed to the supercapacitors with largely improved energy storage performance (Fathy et al. 2016a, b, c, d). The ACTF materials fundamentally comprise of sheets because of auxiliary imperfections, which are relied upon to give dynamic destinations to adsorption. Likewise, vicinity of utilitarian gatherings at the surface of ACTF fundamentally affects their adsorption properties.

\section{Effect of $p H$}

Figure 5 shows the effect of $\mathrm{pH}$ on adsorption of $\mathrm{Na}^{+}$on ACTF. We found that the $\mathrm{pH}$ of arrangement assumes an imperative part on $\mathrm{Na}^{+}$absorption attributes on ACTF. The evacuation of $\mathrm{Na}^{+}$concentration was rapidly at $\mathrm{pH} 2-7$, 


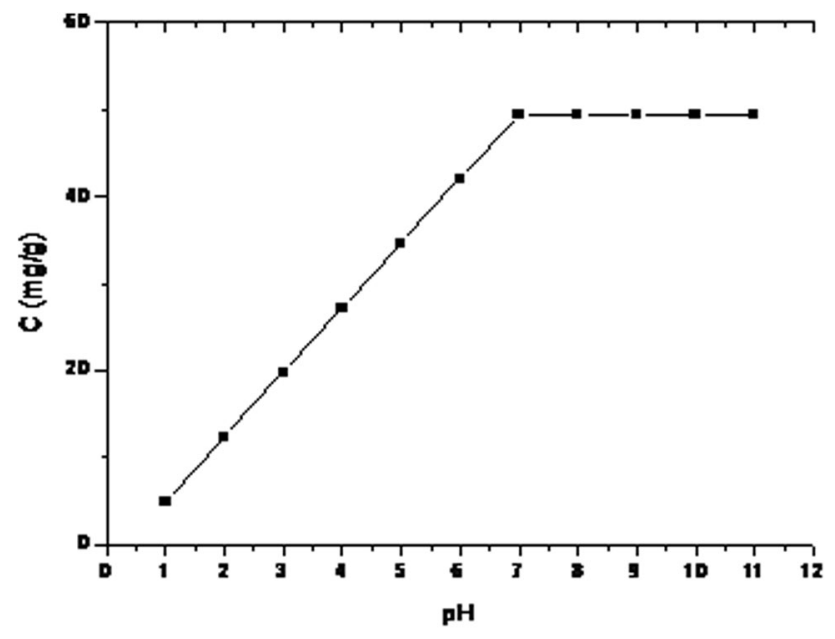

Fig. 5 Effect of $\mathrm{pH}$ on adsorption of $\mathrm{Na}^{+}$on the ACTF carbon nanomaterials

and gradually in the $\mathrm{pH}$ score of 7-11. Harmony centralizations of $\mathrm{Na}^{+}$ionic species, at diverse $\mathrm{pH}$, are a useful premise for the discourse of the adsorption mechanism (Vilvanathan and Shanthakumar 2015; Vinhal et al. 2015). The absorption of sodium ions becomes fixed when the $\mathrm{pH}$ more than seven because of the saturation at active site on the ACTF that specific subtracted experimentally from all available amount of sodium ions, so these are the reliable values of absorbed sodium we obtained. Fig. 5 shows the significant dependence of $\mathrm{Na}^{+}$absorption on ACTF at different $\mathrm{pH}$. The competition between $\mathrm{H}^{+}$and $\mathrm{Na}^{+}$leads to low $\mathrm{Na}^{+}$absorption at low $\mathrm{pH}$. We concluded that $\mathrm{pH}$ higher than 3 is beneficial for the ionization of the acidic surface groups, such as carboxylic groups and others groups ( $\left.\mathrm{p} K_{\mathrm{a}} 3-6\right)$, that play a significant role in the uptake of $\mathrm{Na}^{+}$ions.

\section{Kinetic studies}

From contact time study, we showed that the adsorption of sodium ions from aqueous solution at $\mathrm{pH} 7$ by ACTF is very fast at first $60 \mathrm{~min}$ and that is sufficient to achieve the adsorption equilibrium, as illustrated in Fig. 6.

Analyzing the regression coefficients $\left(R^{2}\right)$, parameters values of the pseudo-first and pseudo-second-order rate adsorption kinetic models were utilized to study the adsorption of sodium ions on ACTF (Fathy et al. 2015a). We found that the parameters of pseudo-second-order are the best fitted to explain the data of contact time study. The separation of the variables of the pseudo-second-order in the differential form and integration are given in the following equation (Sun et al. 2014);

$\frac{t}{q_{t}}=\frac{1}{K^{\prime} q_{\mathrm{e}}^{2}}+\left(\frac{1}{q_{\mathrm{e}}}\right) t$

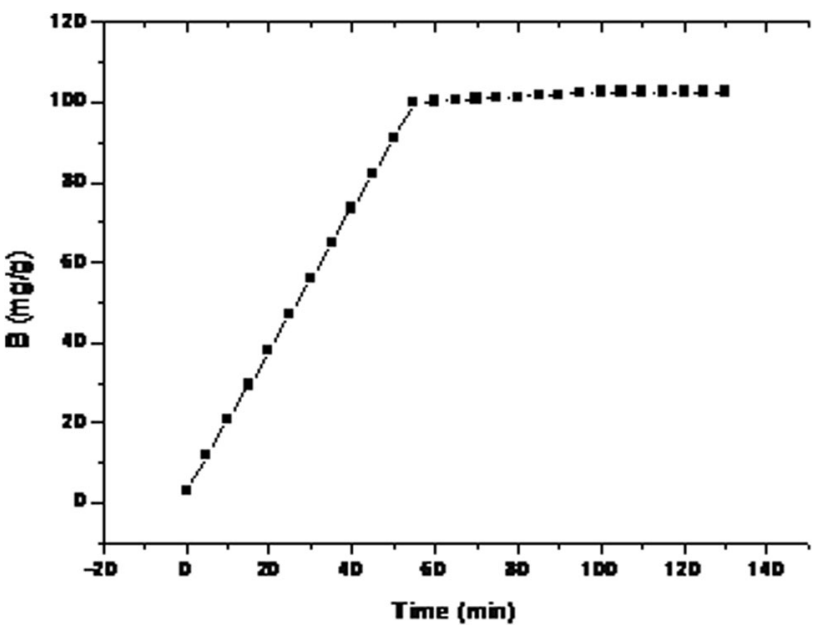

Fig. 6 Effect of time on the adsorption of $\mathrm{Na}^{+}$by ACTF $\left(C\left[\mathrm{Na}^{+}\right]_{0}=500 \mathrm{mg} \mathrm{L}^{-1}, m / V=100 \mathrm{mg} \mathrm{L}^{-1}, \mathrm{pH} 6.2, T=25^{\circ} \mathrm{C}\right)$. Lines pseudo-second-order kinetics model

where $q_{\mathrm{e}}$ and $q_{t}$ are the amounts of metal ion adsorbed $\left(\mathrm{mg} \mathrm{g}^{-1}\right)$ at equilibrium and at time $t$, respectively. $K^{\prime}$ $\left(\mathrm{g} \mathrm{mg}^{-1} \mathrm{~min}^{-1}\right)$ is the pseudo-second-order rate constant of adsorption (Shan et al. 2015; Solgy et al. 2015).

Plotting $t / q_{t}$ against $T$ gives values of $q_{\mathrm{e}}, K$, and $R^{2}$, as shown in (Table 1). The $q_{\mathrm{e}}$ values are viewed good agreement with the results of testing work. The special form in the church of pseudo-second-order kinetics, which is common for that taken away of metal ions by carbonaceous materials, gives a sign of that the concentrations of both support $\mathrm{Na}^{+}$and adsorbent (ACTF) are needed in the rate coming to a decision about the step of the adsorption process. In addition, we indicate that the slower absorption rates on ACTF indicate the adsorption of sodium ions having a higher energetic barrier. It may be such as conception and surface complexion, which are working.

\section{Adsorption isotherms study}

To describe adsorption characteristics of ACTF, two adsorption idealized models have been used, namely, the Langmuir (Eq. 2) (Ofomaja et al. 2013; Reck et al. 2015) and Freundlich (Eq. 3), in their linearized forms:

$q_{\mathrm{e}}=\frac{b q_{\max } C_{\mathrm{e}}}{1+b C_{\mathrm{e}}}$ or $\frac{C_{\mathrm{e}}}{q_{\mathrm{e}}}=\frac{1}{\left(b q_{\max }\right)+C_{\mathrm{e}} / q_{\max }}$,

$q_{\mathrm{e}}=k_{\mathrm{f}} C_{\mathrm{e}}^{n}$ or $\log q_{\mathrm{e}}=\log k_{\mathrm{f}}+n \log C_{\mathrm{e}}$,

Table $1 \mathrm{Na}^{+}$absorption on ACTF and its kinetic parameters of the pseudo-second-order equation

\begin{tabular}{|c|c|c|c|c|}
\hline & $q_{\mathrm{e}}\left(\mathrm{mg} \mathrm{g}^{-1}\right)$ & $K^{\prime}\left(\mathrm{g} \mathrm{mg}^{-1} \min ^{-1}\right) \times 10^{2}$ & $R^{2}$ & $\operatorname{SSE}(\%)$ \\
\hline ACTF & 105 & 3.066 & 0.9999 & 0.00112 \\
\hline
\end{tabular}


where $C_{\mathrm{e}}$ is the equilibrium concentration of metal ions remaining in the solution $\left(\mathrm{mol} \mathrm{L}^{-1}\right) ; q_{\mathrm{e}}$ is a number of metal ions adsorbed per weight unit of solid after equilibrium ( $\mathrm{mol} \mathrm{g}^{-1}$ ); $q_{\max }$ and $b$ are Langmuir constants related to the adsorption capacity and adsorption affinity, respectively (Miyake et al. 2013; Mobasherpour et al. 2014; Nagy et al. 2014), $b\left(\mathrm{~mol}^{-1}\right)$ is a constant show a relation between the heat of adsorption and the greatest point of adsorption capacity, and $q_{\max }$ is the amount of adsorbate at complete monolayer amount covered $\left(\mathrm{mol} \mathrm{g}^{-1}\right)$.

The adsorption capacity represented $k_{\mathrm{f}}\left(\mathrm{mol}^{-1} N \mathrm{Ln}\right.$ $\mathrm{g}^{-1}$ ) when the equilibrium concentration equals to one meanwhile the adsorption on the equilibrium concentration represents by $N$.

The Freundlich and Langmuir adsorption isotherms are shown in Fig. 7, and the isotherm parameters that obtained by fitting the adsorption equilibrium data to the isotherm models were listed in Table 2 . We can note that the $R^{2}$ values for the Langmuir model to be copied are lower at all temperatures than Freundlich. We found that with increasing temperature for all made observation adsorbents, both $Q_{\max }$ and $B$ values were increased.
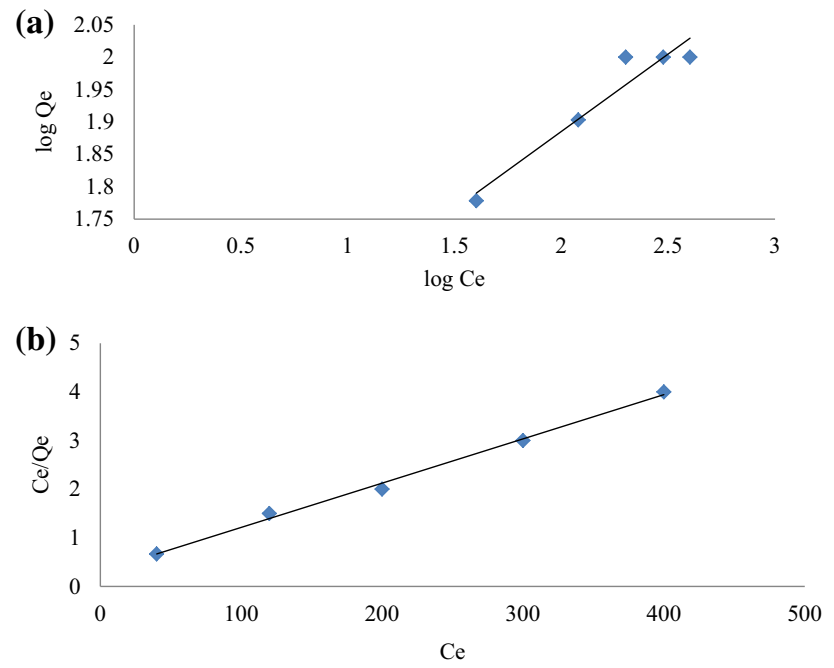

Fig. 7 a Freundlich adsorption isotherms of $\mathrm{Na}^{+}$on the ACTF at 35, 45 , and $65^{\circ} \mathrm{C}$, b Langmuir adsorption isotherms of $\mathrm{Na}^{+}$on the ACTF at 35,45 , and $65{ }^{\circ} \mathrm{C}\left(\mathrm{m} / \mathrm{V}=500 \mathrm{mg} \mathrm{L}^{-1}, \mathrm{pH} 7\right)$
The high values of $Q_{\max }$ and $B$ show that the affinity of sodium ions adsorption on ACTF was achieved with increasing temperatures, suggesting the possible use of functionalized ACTF for removal of $\mathrm{Na}^{+}$ions from saline water or wastewater at higher temperatures values. Langmuir isotherm model that applied for the adsorption process does not give details about the adsorption of $\mathrm{Na}^{+}$on ACTF. The maximum adsorption capacity of sodium ions on ACTF at $65{ }^{\circ} \mathrm{C}$ was $135.45 \mathrm{mg} \mathrm{g}^{-1}$. The results of the isotherm models indicate the lower coordination capability of secondary adsorption process due to higher affinity and availability of primary carboxy group on the metal cation. In the initial adsorption step, the metal cation/carboxylic bond is created involving mainly primary carboxy group that causing a change of structure and flexibility of the alkyl chain on ACTF.

\section{Thermodynamics of adsorption processes}

Enthalpy $(\Delta H)$, The Gibbs free energy $(\Delta G)$, and entropy $(\Delta S)$ of the adsorption processes were calculated using the following equations (Meitei and Prasad 2014; Luo et al. 2015):

$\Delta G^{0}=-R T \ln (55.5 b)$,

$\ln (55.5 b)=\frac{\Delta S^{0}}{R}-\frac{\Delta H^{0}}{R T}$,

where $T$ is the temperature, and $\mathrm{K}$ and $\mathrm{R}$ are the universal gas constant $\left(8.314 \mathrm{~J} \mathrm{~mol}^{-1} \mathrm{~K}^{-1}\right.$ ) (Liu et al. 2013, Lu et al. 2014). The Langmuir join of substance on constants $a$ and $b$ was formed from the isotherm experiments. $\Delta H$ and $\Delta S$ can be obtained from the slope and intercept of the linear plots of $\ln (55.5 b)$ versus $T^{-1}$, respectively, assuming the adsorption kinetics to be under steady-state conditions. The data well-fitting and confirmed if the $R^{2}$ has high values with low standard errors of the estimated thermodynamic parameters. The calculated thermodynamic values (Table 3) give some information concerning the adsorption mechanism for the studied ACTF.

$\mathrm{Na}^{+}$absorption on ACTF is a spontaneous process and that clear from the negative values of $\Delta G$. We detect that the $\Delta G$ values decrease with increasing temperature, indicating higher spontaneity at higher temperatures. At higher

Table 2 Isotherm parameters Langmuir and Freundlich for $\mathrm{Na}^{+}$absorption on ACTF

\begin{tabular}{|c|c|c|c|c|c|c|}
\hline \multirow[t]{2}{*}{$T\left({ }^{\circ} \mathrm{C}\right)$} & \multicolumn{3}{|c|}{ Langmuir parameters } & \multicolumn{3}{|c|}{ Freundlich parameters } \\
\hline & $K$ & $q_{\mathrm{e}}$ & $R^{2}$ & $n$ & $\operatorname{Ln} K$ & $R^{2}$ \\
\hline 308 & 0.029828 & 109.9369 & 0.997741 & 4.181521 & 1.4 & 0.992379 \\
\hline 318 & 0.00338 & 129.401 & 0.65588 & 0.586692 & 1.5 & 0.993225 \\
\hline 338 & 0.00513 & 135.165 & 0.64046 & 0.839562 & 0.07 & 0.983452 \\
\hline
\end{tabular}


Table $3 \mathrm{Na}^{+}$adsorption thermodynamic parameters onto ACTF

\begin{tabular}{cllll}
\hline$T\left({ }^{\circ} \mathrm{C}\right)$ & \multicolumn{4}{l}{ Thermodynamic parameters } \\
\cline { 2 - 4 } & $\Delta G\left(\mathrm{KJ} \mathrm{mol}^{-1}\right)$ & $\Delta H\left(\mathrm{KJ} \mathrm{mol}^{-1}\right)$ & $\Delta S\left(\mathrm{~J} \mathrm{~mol}^{-1} \mathrm{~K}^{-1}\right)$ & $R^{2}$ \\
\hline $\mathrm{ACTF}$ & & & \\
35 & -12035.1 & 6493.16 & 5541.944 & 0.9924 \\
45 & -14071.2 & & \\
65 & -12264.1 & & \\
\hline
\end{tabular}

temperatures, $\mathrm{Na}^{+}$ions are readily desolvated. Its diffusion through the medium and within the pores (intra-particle diffusion) is faster processes contributing to a higher probability of $\mathrm{Na}^{+}$absorption. We found that free energy change for physisorption is general between -20 and $0 \mathrm{~kJ} \mathrm{~mol}^{-1}$. In addition, the physisorption together with chemisorption lays within -20 to $-80 \mathrm{~kJ} \mathrm{~mol}^{-1}$, whereas the pure conception has free energy change obtained in the range of -80 to $-400 \mathrm{~kJ} \mathrm{~mol}^{-1}$ as reported by Hyder et al. (2015), Kumar and Tamilarasan (2013), and Koyuncu and Kul (2014).

The worked out $\Delta G$ also suggest that $\mathrm{Na}^{+}$adsorbents having the sorption processes under observation could be thought of application of both chemisorption and physisorption processes mechanism. The $\Delta H^{0}$ positive values indicate that the $\mathrm{Na}^{+}$adsorption process on the surface of ACTF is better at higher temperature operations like nuclear power stations and that it is an endothermic process. Those values about endothermic of adsorption processes make clear to a positive entropy change which gives a sign of possible adsorption.

We found that the high connection, of $\mathrm{Na}^{+}$ion, adsorbed on ACTF leads to positive entropy change. The positive values of $\Delta S$ indicate a tendency to the higher randomness of the studied system at equilibrium or such structural changes at the surface interface of $\mathrm{Na}^{+}$loaded on ACTF which could contribute to positive entropy change. The definite degree of orderliness could be expected at the $\mathrm{Na}^{+} /$ACTF interface, but regardless of that, overall adsorption process is entropy driven. In addition, some processes, such as ion exchange, could also contribute to positive entropy change (Fathy et al. 2014).

\section{Mechanism of adsorption of sodium ions on ACTF}

We can suggest that the porous structures, in terms of area, pore volume, and pore distribution, were important properties of ACTF and determined the performance of carbon during adsorption. Some studies found that with the increase of the specific surface area of the activated carbon, the adsorption capacity increased. Meanwhile, other studies had shown that in liquid phase adsorption, micropores were the major provider of adsorption sites, and played an important role in the activated carbon adsorption (Fathy et al. 2016a, b, c, d; Hosny et al. 2016).

As can be seen from kinetics model that sodium ions adsorption on ACTF generated a unilinear curve for adsorption. In addition, we can say that sodium ions adsorption on ACTF were composed of three consecutive process including film diffusion, intra-particle diffusion, and surface adsorption (Fathy et al. 2016a, b, c, d). In general, in the case of adsorption from the liquid phase to solid phase, the adsorption capacity of any carbonaceous adsorbent for ions, such as sodium ions, depends on the following factors:

- The physical nature of the adsorbent, such as pore structure, and the presence of surface functional groups;

- the nature of the adsorbate, such as its $\mathrm{p} K \mathrm{a}$, functional groups present, polarity, molecular weight, and size;

- the conditions of the solution, such as $\mathrm{pH}$, ionic strength, as well as the adsorbate concentration.

\section{Conclusions}

The adsorption of $\mathrm{Na}^{+}$on ACTF was studied, and two kinds of experimental data sets showed that the adsorption affinity of $\mathrm{Na}^{+}$on ACTF has a high value of interest. We discovered that oxidation process is increasing the adsorption and ion exchange properties of ACTF. The change in adsorption capacities of ACTF increased with temperature. The overall adsorption capacity of ACTF on $\mathrm{Na}^{+}$is $45 \%$. The kinetic data of the adsorption on the investigated ACTF were well fitted with the pseudo-second-order kinetic model, suggesting that the rate-limiting step was chemical adsorption rather than diffusion. The adsorption experimental data of $\mathrm{Na}^{+}$on ACTF follow the Freundlich adsorption isotherms. The adsorption of $\mathrm{Na}^{+}$on the studied ACTF is a rather complex and spontaneous process, suggesting that the mechanism includes both physisorption and chemisorption mechanisms. The adsorption experiments with functionalized ACTF and their influence on adsorption capacities are currently under investigation in our laboratory.

Open Access This article is distributed under the terms of the Creative Commons Attribution 4.0 International License (http:// creativecommons.org/licenses/by/4.0/), which permits unrestricted use, distribution, and reproduction in any medium, provided you give appropriate credit to the original author(s) and the source, provide a link to the Creative Commons license, and indicate if changes were made. 


\section{References}

Bertrand-Drira C, Cheng X-W, Cacciaguerra T, Trens P, Melinte G, Ersen O, Minoux D, Finiels A, Fajula F, Gerardin C (2015) Mesoporous mordenites obtained by desilication: mechanistic considerations and evaluation in catalytic oligomerization of pentene. Microporous Mesoporous Mater 213:142-149

Bevilacqua M, Babutskyi A, Chrysanthou A (2015) A review of the catalytic oxidation of carbon-carbon composite aircraft brakes. Carbon 95:861-869

Clarke DP, Al-Abdeli YM, Kothapalli G (2015) Multi-objective optimisation of renewable hybrid energy systems with desalination. Energy 88:457-468

Cohen-Tanugi D, Grossman JC (2015) Nanoporous graphene as a reverse osmosis membrane: recent insights from theory and simulation. Desalination 366:59-70

da Silva MEV, Schwarzer K, Pinheiro FN, Rocha PAC, de Andrade CF (2015) Experimental study of tray materials in a thermal desalination tower with controlled heat source. Desalination 374:38-46

Da X, Wen J, Lu Y, Qiu M, Fan Y (2015) An aqueous sol-gel process for the fabrication of high-flux YSZ nanofiltration membranes as applied to the nanofiltration of dye wastewater. Sep Purif Technol 152:37-45

Date A, Vahaji S, Andrews J, Akbarzadeh A (2015) Experimental performance of a rotating two-phase reaction turbine. Appl Therm Eng 76:475-483

Del-Pilar-Ruso Y, Martinez-Garcia E, Giménez-Casalduero F, LoyaFernández A, Ferrero-Vicente LM, Marco-Méndez C, de-laOssa-Carretero JA, Sánchez-Lizaso JL (2015) Benthic community recovery from brine impact after the implementation of mitigation measures. Water Res 70:325-336

Deng D, Aouad W, Braff WA, Schlumpberger S, Suss ME, Bazant MZ (2015) Water purification by shock electrodialysis: deionization, filtration, separation, and disinfection. Desalination 357:77-83

Deshmukh A, Yip NY, Lin S, Elimelech M (2015) Desalination by forward osmosis: identifying performance limiting parameters through module-scale modeling. J Membr Sci 491:159-167

Dinda M, Chatterjee U, Kulshrestha V, Sharma S, Ghosh S, Desale GR, Shahi VK, Makwana BS, Maru PD, Bhadja V, Maiti S, Ghosh PK (2015) Sustainable synthesis of a high performance inter-polymer anion exchange membrane employing concentrated solar radiation in a crucial functionalization step. J Membr Sci 493:373-381

El-Sayed M, Ramzi M, Hosny R, Fathy M, Moghny TA (2016) Breakthrough curves of oil adsorption on novel amorphous carbon thin film. Water Sci Technol 73(10):2361-2369

Fathy M, Moghny TA, Awadallah AE, El-Bellihi AHAA (2014) Adsorption kinetics of sulfates by anion exchange resin containing pristine multiwalled carbon nano tubes. Glob J Res Eng C Chem Eng 1(14)

Fathy M, Moghny TA, Abdou MM, El-Bellihi AAAH (2015a) Study the adsorption of $\mathrm{Ca}(\mathrm{II})$ and $\mathrm{Mg}$ (II) on high crosslinked polystyrene divinyl benzene resin. Int J Mod Chem 7(1):36-44

Fathy M, Moghny TA, Ahmed EA, Moaz MA, Abdel-Hameed AAEB (2015b) Development of sulfonated nanocomposites ion exchange resin for removal of sodium ions from saline water. Int J Mod Org Chem 4(1):62-69

Fathy M, Moghny TA, Mousa MA, El-Bellihi AHAA, Awadallah AE (2016a) Absorption of calcium ions on oxidized graphene sheets and study its dynamic behavior by kinetic and isothermal models. Appl Nanosci 6(8):1105-1117. doi:10.1007/s13204016-0537-8

Fathy M, Moghny TA, Mousa MA, El-Bellihi AHAA, Awadallah AE (2016b) Synthesis of transparent amorphous carbon thin films from cellulose powder in rice straw. Arab J Sci Eng 42(1):225-233

Fathy M, Moghny TA, Mousa MA, El-Bellihi AHAA, Awadallah Ahmed E (2016c) Absorption of calcium ions on oxidized graphene sheets and study its dynamic behavior by kinetic and isothermal models. Appl Nanosci. doi:10.1007/s13204-1301610537-13208

Fathy M, Moghny TA, Mousa MA, El-Bellihi AHAA, Awadallah Ahmed E (2016d) Synthesis of transparent amorphous carbon thin films from cellulose powder in rice straw. Arab J Sci Eng. doi:10.1007/s13369-13016-12273-13365

Hau NT, Chen S-S, Nguyen NC, Huang KZ, Ngo HH, Guo W (2014) Exploration of EDTA sodium salt as novel draw solution in forward osmosis process for dewatering of high nutrient sludge. J Membr Sci 455:305-311

Hosny R, Fathy M, Ramzi M, Moghny TA, Desouky S, Shama S (2016) Treatment of the oily produced water (OPW) using coagulant mixtures. Egypt J Pet 25(3):391-396

Hyder AHMG, Begum SA, Egiebor NO (2015) Adsorption isotherm and kinetic studies of hexavalent chromium removal from aqueous solution onto bone char. J Environ Chem Eng 3(2):1329-1336

Jodeh S, Abdelwahab F, Jaradat N, Warad I, Jodeh W (2016) Adsorption of diclofenac from aqueous solution using Cyclamen persicum tubers based activated carbon (CTAC). J Assoc Arab Univ Basic Appl Sci 20:32-38

Koyuncu H, Kul AR (2014) An investigation of $\mathrm{Cu}(\mathrm{II})$ adsorption by native and activated bentonite: kinetic, equilibrium and thermodynamic study. J Environ Chem Eng 2(3):1722-1730

Kumar M, Tamilarasan R (2013) Kinetics, equilibrium data and modeling studies for the sorption of chromium by Prosopis juliflora bark carbon. Arab J Chem. doi:10.1016/j.arabjc.2013. 05.025

Liu K, Zhu B, Feng Q, Wang Q, Duan T, Ou L, Zhang G, Lu Y (2013) Adsorption of $\mathrm{Cu}(\mathrm{II})$ ions from aqueous solutions on modified chrysotile: thermodynamic and kinetic studies. Appl Clay Sci 80-81:38-45

Lu M, Zhang Y-M, Guan X-H, Xu X-H, Gao T-T (2014) Thermodynamics and kinetics of adsorption for heavy metal ions from aqueous solutions onto surface amino-bacterial cellulose. Trans Nonferrous Metals Soc China 24(6):1912-1917

Luo Z, Gao M, Yang S, Yang Q (2015) Adsorption of phenols on reduced-charge montmorillonites modified by bispyridinium dibromides: mechanism, kinetics and thermodynamics studies. Colloids Surf A 482:222-230

Mehta K, Farnaud S, Patel VB (2016) Molecular effects of alcohol on iron metabolism. Molecular aspects of alcohol and nutrition. Academic Press, San Diego, pp 355-368

Meitei MD, Prasad MNV (2014) Adsorption of Cu (II), Mn(II) and Zn (II) by Spirodela polyrhiza (L.) Schleiden: equilibrium, kinetic and thermodynamic studies. Ecol Eng 71:308-317

Miyake Y, Ishida H, Tanaka S, Kolev SD (2013) Theoretical analysis of the pseudo-second order kinetic model of adsorption. Application to the adsorption of $\mathrm{Ag}(\mathrm{I})$ to mesoporous silica microspheres functionalized with thiol groups. Chem Eng J 218:350-357

Mobasherpour I, Salahi E, Ebrahimi M (2014) Thermodynamics and kinetics of adsorption of $\mathrm{Cu}$ (II) from aqueous solutions onto multi-walled carbon nanotubes. J Saudi Chem Soc 18(6):792-801

Nagy B, Măicăneanu A, Indolean C, Mânzatu C, Silaghi-Dumitrescu L, Majdik C (2014) Comparative study of Cd(II) biosorption on cultivated Agaricus bisporus and wild Lactarius piperatus based biocomposites. Linear and nonlinear equilibrium modelling and kinetics. J Taiwan Inst Chem Eng 45(3):921-929 
Nguyen NN, Nguyen AV (2015) The dual effect of sodium halides on the formation of methane gas hydrate. Fuel 156:87-95

Ofomaja AE, Pholosi A, Naidoo EB (2013) Kinetics and competitive modeling of cesium biosortion onto chemically modified pine cone powder. J Taiwan Inst Chem Eng 44(6):943-951

Reck JM, Pabst TM, Hunter AK, Wang X, Carta G (2015) Adsorption equilibrium and kinetics of monomer-dimer monoclonal antibody mixtures on a cation exchange resin. J Chromatogr A 1402:46-59

Reddy N, Yang Y (2008) Characterizing natural cellulose fibers from velvet leaf (Abutilon theophrasti) stems. Biores Technol 99(7):2449-2454

Shan RR, Yan LG, Yang K, Hao YF, Du B (2015) Adsorption of $\mathrm{Cd}(\mathrm{II})$ by $\mathrm{Mg}-\mathrm{Al}-\mathrm{CO}_{3}-$ and magnetic $\mathrm{Fe}_{3} \mathrm{O}_{4} / \mathrm{Mg}-\mathrm{Al}-\mathrm{CO}_{3}$ layered double hydroxides: kinetic, isothermal, thermodynamic and mechanistic studies. J Hazard Mater 299:42-49

Sharma P, Saikia BK, Das MR (2014) Removal of methyl green dye molecule from aqueous system using reduced graphene oxide as an efficient adsorbent: kinetics, isotherm and thermodynamic parameters. Colloids Surf A 457:125-133

Singh K, Sinha TJM, Srivastava S (2015) Functionalized nanocrystalline cellulose: smart biosorbent for decontamination of arsenic. Int J Miner Process 139:51-63

Solgy M, Taghizadeh M, Ghoddocynejad D (2015) Adsorption of uranium(VI) from sulphate solutions using Amberlite IRA-402 resin: equilibrium, kinetics and thermodynamics study. Ann Nucl Energy 75:132-138

Sun W-L, Xia J, Shan Y-C (2014) Comparison kinetics studies of $\mathrm{Cu}$ (II) adsorption by multi-walled carbon nanotubes in homo and heterogeneous systems: effect of nano- $\mathrm{SiO}_{2}$. Chem Eng J 250:119-127

Valentini L, Cantalini C, Lozzi L, Picozzi S, Armentano I, Kenny JM, Santucci S (2004) Effects of oxygen annealing on cross sensitivity of carbon nanotubes thin films for gas sensing applications. Sens Actuators B 100(1-2):33-40

Vilvanathan S, Shanthakumar S (2015) Biosorption of Co(II) ions from aqueous solution using Chrysanthemum indicum: kinetics, equilibrium and thermodynamics. Process Saf Environ Prot 96:98-110

Vinhal JO, Lage MR, Carneiro JWM, Lima CF, Cassella RJ (2015) Modeling, kinetic, and equilibrium characterization of paraquat adsorption onto polyurethane foam using the ion-pairing technique. J Environ Manage 156:200-208

Wang L, Xing R, Liu S, Yu H, Qin Y, Li K, Feng J, Li R, Li P (2010) Recovery of silver (I) using a thiourea-modified chitosan resin. J Hazard Mater 180(1-3):577-582

Xia L, Hu Y-X, Zhang B-H (2014) Kinetics and equilibrium adsorption of copper(II) and nickel(II) ions from aqueous solution using sawdust xanthate modified with ethanediamine. Trans Nonferrous Metals Soc China 24(3):868-875

Yang S, Li L, Pei Z, Li C, Lv J, Xie J, Wen B, Zhang S (2014) Adsorption kinetics, isotherms and thermodynamics of $\mathrm{Cr}$ (III) on graphene oxide. Colloids Surf A 457:100-106

Yang C, Li L, Shi J, Long C, Li A (2015) Advanced treatment of textile dyeing secondary effluent using magnetic anion exchange resin and its effect on organic fouling in subsequent RO membrane. J Hazard Mater 284:50-57

Yari M, Rajabi M, Moradi O, Yari A, Asif M, Agarwal S, Gupta VK (2015) Kinetics of the adsorption of $\mathrm{Pb}$ (II) ions from aqueous solutions by graphene oxide and thiol functionalized graphene oxide. J Mol Liq 209:50-57

Zhao F, Repo E, Yin D, Sillanpää MET (2013) Adsorption of Cd(II) and $\mathrm{Pb}$ (II) by a novel EGTA-modified chitosan material: kinetics and isotherms. J Colloid Interface Sci 409:174-182

Zhou L, Pan S, Chen X, Zhao Y, Zou B, Jin M (2014) Kinetics and thermodynamics studies of pentachlorophenol adsorption on covalently functionalized $\mathrm{Fe}_{3} \mathrm{O}_{4} @ \mathrm{SiO}_{2}-\mathrm{MWCNT}$ core-shell magnetic microspheres. Chem Eng J 257:10-19

Zhu J, Guo N, Zhang Y, Yu L, Liu J (2014) Preparation and characterization of negatively charged PES nanofiltration membrane by blending with halloysite nanotubes grafted with poly (sodium 4-styrenesulfonate) via surface-initiated ATRP. J Membr Sci 465:91-99

Zhu H-X, Cao X-J, He Y-C, Kong Q-P, He H, Wang J (2015) Removal of $\mathrm{Cu}^{2+}$ from aqueous solutions by the novel modified bagasse pulp cellulose: kinetics, isotherm and mechanism. Carbohyd Polym 129:115-126

Zuyi T, Hui Z, Baolin Z (1995) Thermodynamic functions for ion exchange of amino acid. React Funct Polym 27(1):29-33 